\title{
Influence of amino acids on the formation of mutagenic/ carcinogenic heterocyclic amines in a model system
}

\author{
Maria A.E.Johansson ${ }^{3}$, Laurent B.Fay', Gian A.Gross ${ }^{1}$, \\ Kjell Olsson ${ }^{2}$ and Margaretha Jägerstad \\ Department of Applied Nutrition and Food Chemistry, Chemical Centre, \\ Lund University, PO Box 124, S-221 00 Lund, Sweden, 'Nestec Ltd, Nestle \\ Research Centre, PO Box 44, Vers-chez-les-Blanc, CH-1000 Lausanne 26, \\ Switzerland and ${ }^{2}$ Department of Chemistry, Swedish University of \\ Agricultural Sciences, PO Box 7015, S-750 07 Uppsala, Sweden \\ ${ }^{3}$ To whom correspondence should be addressed
}

Mixtures of creatinine, glucose and various single amino acids were heated at $180^{\circ} \mathrm{C}$ for $10 \mathrm{~min}$ in an aqueous model system. The heated mixtures all showed mutagenic activity, ranging from 80 to 2400 TA98 revertant colonies/ $\mu$ mol creatinine with metabolic activation. Testing of HPLC fractions for mutagenic activity showed each mixture to contain several mutagenic components, some of which corresponded to known heterocyclic amines and others to unknown compounds. The presence of 2-amino-3-methyl-imidazo[4,5-f]quinoxaline, 2 amino-3,8-dimethylimidazo[4,5-f]quinoxaline and 2-amino3,7,8-trimethylimidazo[4,5-f] quinoxaline in most of the samples was established using HPLC with photodiode array detection and liquid chromatography/mass spectrometry with electrospray interface and single ion monitoring. In addition, 2-amino-3,4,8-trimethylimidazo[4,5-f]quinoxaline, 2-amino1-methyl-6-phenylimidazo[4,5-b]pyridine, 3-amino-1,4-dimethyl-5H-pyrido $[4,3-b]$ indole and 3-amino-1-methyl-5H pyrido $[4,3-b]$ indole and the co-mutagenic compounds $9 H$ pyrido $[3,4-b]$ indole and 1-methyl-9H-pyrido $[3,4-b]$ indole were detected in some samples.

\section{Introduction}

The major food mutagens isolated to date from cooked meat and fish products are heterocyclic amines (HAs*). Since first reported by Sugimura et al. (1), much effort has been devoted to identifying and quantifying these compounds and to understanding the mechanisms of their formation (for reviews see 2,3). Most of the mutagenic heterocyclic amines formed at normal cooking temperatures are imidazoquinolines or imidazoquinoxalines (IQ compounds), imidazopyridines (e.g. 2-amino-1-methyl-6-phenylimidazo[4,5-b]pyridine; PhIP) or imidazofuropyridines (4-6).

Many HAs are multipotent carcinogens in long-term rodent bioassays (for a review see 7), with 2-amino-3-methylimid-

\footnotetext{
-Abbreviations: HA(s), heterocyclic amine(s); PhIP, 2-amino-1-methyl-6phenylimidazo[4,5-b]pyridine; IQ, 2-amino-3-methylimidazo[4,5-f]quinoline; IQx, 2-amino-3-methylımidazo[4,5-flquinoxaline; MeIQ, 2-amuno-3,4dimethylımidazo[4,5-f]quinoline; MeIQx, 2-amino-3,8-dimethylimidazo[4,5f]quinoxaline; 4,8-DiMelQx, 2-amino-3,4,8-trimethylimidazo[4,5-f]quinoxaline; LC/MS, liquid chromatography/mass spectrometry; 7,8-DiMelQx, 2amino-3,7,8-trimethylimidazo[4,5-f]quinoxaline; Glu-P-1, 2-amino-6-methyl-

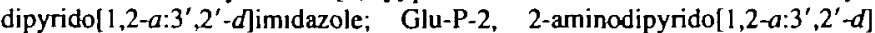
imidazole; Trp-P-1, 3-amino-1,4-dimethyl-5H-pyrido[4,3-b]indole; Trp-P-2, 3-amino-1-methyl-5H-pyrido|4,3-b]indole; harman, 1-methyl-9H-pyrido[3,4b] indole; northarman, $9 H$-pyrido[3,4-b]indole.
}

azo[4,5-f]quinoline (IQ) also positive in primates (8). Epidemiological studies have shown a relationship between the consumption of fried meat products and an elevated risk of colon and other cancers (9-13). The HAs are animal carcinogens and the IARC classified several of them as possible or probable (IQ) human carcinogens (14-16). Efforts to minimize their formation in cooked foods are therefore of great importance and a better understanding of the formation mechanism is needed. Simple modelling experiments have been useful in providing basic information on precursors, inhibitors and the effect of reaction conditions and a good correlation between the formation of HAs in cooked foods and model systems has been observed (for reviews see 3,17).

All details of the formation mechanism of HAs have not yet been clarified. Jägerstad et al. (18) suggested that IQ compounds may be produced via the Maillard reaction from creatin(in)e, amino acids and hexoses present in foods of animal origin (see Scheme 1). This hypothesis has been confirmed by heating creatin(in)e, amino acids and sugars in various model systems, resulting in the formation of IQ, 2amino-3-methylimidazo[4,5-f]quinoxaline (IQx), 2-amino-3,4dimethylimidazo[4,5-f]quinoline (MeIQ), 2-amino-3,8-dimethylimidazo[4,5-f]quinoxaline (MeIQx), 2-amino-3,4,8-trimethylimidazo[4,5-f]quinoxaline (4,8-DiMelQx) and PhIP (for reviews see 3,19 ). Also, ${ }^{14} \mathrm{C}$-labelled glucose was shown to be incorporated into IQx, MeIQx and 4,8-DiMeIQx using an aqueous model system (20). Alternative routes for the formation of HAs may exist, since their formation from creatin(in)e and amino acids has also been observed in the absence of sugar in dry heating model experiments. However, the yield of HAs in the absence of sugar is usually lower (for a review see 3 ).

According to the hypothesis illustrated in Scheme 1, amino acids act as precursors of HAs partly by serving as a nitrogen source in pyridine or pyrazine formation (18). However, mutagenic activity and HA yield previously reported in model systems vary depending on the particular amino acid used (for reviews see 3,17 ). These variations were not completely explained and, so far, the ability to produce mutagenic activity in a model system has been investigated for less than half the naturally occurring amino acids, and even fewer amino acids have been tested as precursors of HAs.

This study was performed to further investigate the effect of various amino acids on the yield and nature of HAs formed in a model system and to increase the understanding of the reactions behind the formation of HAs. Model mixtures, each containing creatinine, glucose and one of the most common amino acids, were heated at $180^{\circ} \mathrm{C}$ for $10 \mathrm{~min}$. The heated mixtures were tested for mutagenic activity using Salmonella typhimurium TA98 with metabolic activation. Furthermore, the model mixtures were purified using the propylsulphonic acidsilica gel tandem extraction method (21) and analysed for known HAs using HPLC with a photodiode array and fluorescence detection and liquid chromatography/mass spectrometry (LC/MS) with electrospray ionization and single ion monitoring. The HPLC fractions were tested for mutagenic activity. 


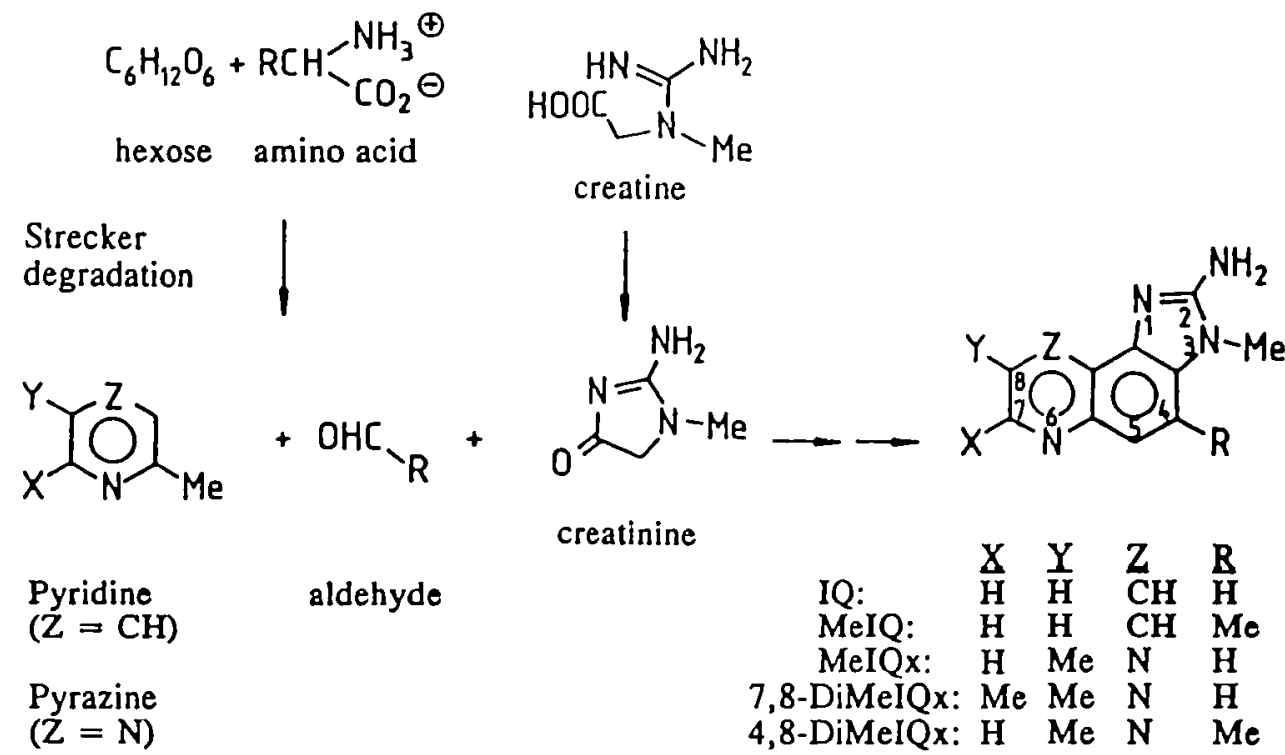

Scheme 1. Suggested pathway for the formation of imidazoquınolines and imidazoquinoxalines (18).

\section{Materials and methods}

\section{Chemicals}

All chemicals and solvents were of HPLC or analytical grade. The solvents, e.g. acetonitrile, methanol and dichloromethane, were purchased from Merck AG (Darmstadt, Germany). Water was obtained from a Milli-Q water purification system (Millipore, Bedford, MA). Creatinine and amino acids were obtained from Sigma Chemical Co. (St Louis, MO) and glucose from BDH Chemicals LId (Dorset, UK). Synthetic IQ, IQx, MeIQ, MeIQx, 4,8-DiMeIQx, 2-amino-3,7,8-trimethylimidazo[4,5-f]quinoxaline (7,8-DiMeIQx), PhIP, 2amino-6-methyl-dipyrido[1,2-a:3',2'-d] imidazole (Glu-P-1), 2-aminodipyr-

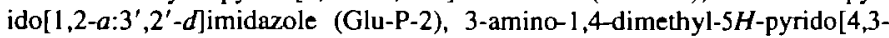
$b$ ]indole (Trp-P-1), 3-amino-1-methyl-5H-pyrido[4,3-b] indole (Trp-P-2) and 1methyl-9H-pyrido[3,4-b]indole (harman) were obtauned from Toronto Research Chemicals (Downsview, Ontario, Canada) and $9 H$-pyrido[3,4- $b$ ] indole (norharman) from Aldrich (Steinheim, Germany). The materials used for propylsulphonic acid-silica gel tandem extraction (Extrelut and BondElut, e.g. PRS and $\mathrm{C}_{18}$ ) were obtained from Merck AG (Darmstadt, Germany) and Analytichem International (Sorbent, Västra Frölunda, Sweden).

\section{Sample preparation}

Samples were prepared by heating creatinine, glucose and various amino acids in an aqueous model system as previously described (22). In brief, creatinine $(0.9 \mathrm{mmol})$, glucose $(0.45 \mathrm{mmol})$ and either $(0.9 \mathrm{mmol})$ glycine, alanine, valine, leucine, isoleucine, serine, threonine, aspartic acid, asparagine, glutamic acid, glutamine, lysine, arginine, histidine, phenylalanine, tyrosine, tryptophan, cysteine, cystine, methionine, prolıne or hydroxyproline were dissolved in 2.5 $\mathrm{ml}$ water and heated for $10 \mathrm{~min}$ at $180^{\circ} \mathrm{C}$ in sealed test tubes. A blank sample (without any amino acid) was prepared concurrently.

After heating the samples were purified using the solid phase extraction method of Gross (21) with some minor modifications (22). Using this method a polar extract (contaning the IQ-type HAs and glutamic actd pyrolysates) and a non-polar extract (containing pyridonndoles) were obtained. Only the polar extract was analysed for HAs in this study.

\section{HPLC fractionation for mutagenic activity profiles}

Extract residues obtained after purification were dissolved in $250 \mu \mathrm{HPLC}$ buffer A (see below) and aliquots $(30 \mu \mathrm{l})$ were injected (Varian 9100 Autosampler) into a Varian 9010 Liquid Chromatograph with a photodiode array UV detector (Varian 9065 , Polychrom) equipped with a ToyoSoda TSK Gel ODS 80TM column $(250 \times 4.6 \mathrm{~mm}$ i.d., $5 \mu \mathrm{m}$ particle size; Varian, Stockholm, Sweden) and a pre-column (Supelguard LC-18-DB, $20 \times 4.6 \mathrm{~mm}$ i.d.) and eluted with a mobile phase of $10 \mathrm{mM}$ aqueous triethylamine adjusted with acetic acid to $\mathrm{pH} 3.2$ (A) or $\mathrm{pH} 3.6$ (B) and acetonitrile (C). A gradient of $5-15 \% \mathrm{C}$ in $\mathrm{A}$ for $10 \mathrm{~min}$, then $15-25 \% \mathrm{C}$ in $\mathrm{B}$ for $10 \mathrm{~min}$ and finally $25-55 \% \mathrm{C}$ in $\mathrm{B}$ for $5 \mathrm{~min}$ was used. The flow rate was $1 \mathrm{~mL} / \mathrm{min}$ and the effluent was monitored at $263 \mathrm{~nm}$. Fractions were collected every $30 \mathrm{~s}$ between 8 and $30 \mathrm{~min}$ and lyophilized before assaying for mutagenic activity.
Table I. Mutagenic activity of model mixtures containing creatinine, glucose and various amino acids heated at $180^{\circ} \mathrm{C}$ for $10 \mathrm{mun}$

\begin{tabular}{lc}
\hline Amino acid & Mutagenic activity" \\
\hline Cysteine & 2420 \\
Cystine & 2251 \\
Threonine & 796 \\
Lysine & 556 \\
Serine & 483 \\
Alanine & 478 \\
Histidine & 439 \\
Asparagine & 432 \\
Tyrosine & 322 \\
Arginine & 314 \\
Glutamine & 306 \\
Glycine & 290 \\
Aspartic acid & 271 \\
Methionine & 262 \\
Isoleucine & 261 \\
Proline & 240 \\
Valine & 240 \\
Leucine & 198 \\
Hydroxyproline & 177 \\
Tryptophan & 102 \\
Glutamic acid & 92 \\
Phenylalanine & 83 \\
\hline
\end{tabular}

TA98 revertants $/ \mu \mathrm{mol}$ creatinine, with metabolic actuvation from the linear portion of dose-response curves from replicate platings.

\section{Mutation assay}

The mutagenic activity of the lyophilized HPLC fractions was tested as described by Ames et al. (23) using Salmonella strain TA 98 with the addition of $0.5 \mathrm{ml} \mathrm{S} 9 \mathrm{mux}$ containing $5 \%$ chlorophene-induced rat liver/plate (24). The fractions were tested at single doses. Crude heated model mixtures were tested in duplicate at three different doses to establish dose-response curves. The number of revertants/ $/ \mathrm{mol}$ original creatinine was calculated from the linear part of the curve (25). Synthetic MelQx was used as a positive control (50 000 revertants $/ \mu \mathrm{g}$ ). The colonies were counted in an automated colony counter using the software Cream ${ }^{\mathrm{TM}}$ (Kem-En-Tec, Copenhagen, Denmark). The spontaneous reversion rate was 30-35 revertants/plate. A fraction or sample was considered mutagenic if it induced revertants to twice the background level.

Identification and quantification of HAs using HPLC

The HAs extracted from the heated model systems were identified and quantified by HPLC employing a Hewlett Packard 1090M system containing 

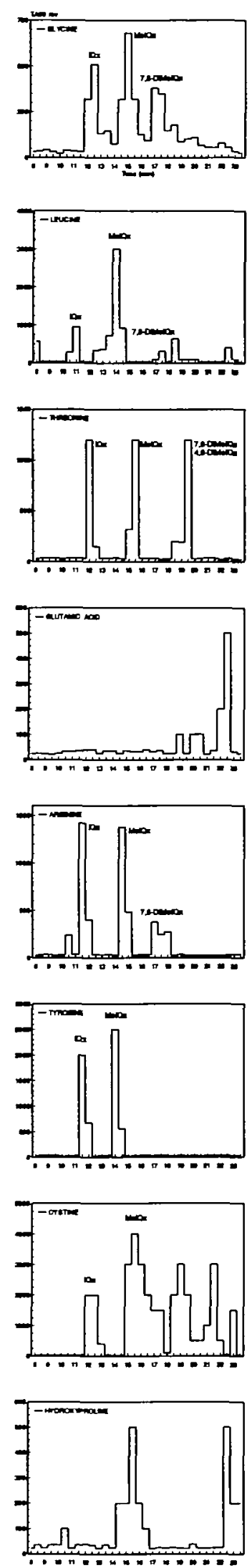
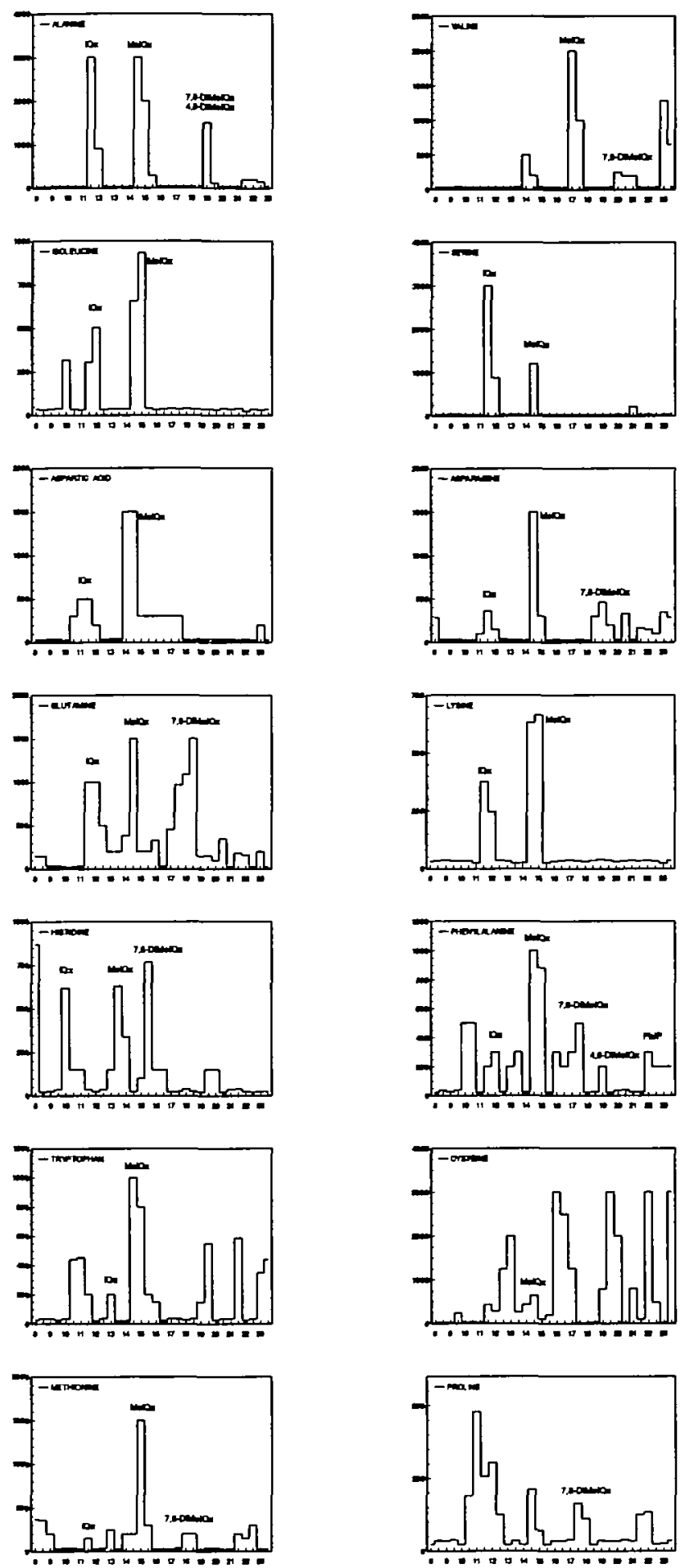

Figure 1. Mutagenic activity in TA98 with metabolic activation in fractions from HPLC separation of heated model mixtures containing various amino acids. Mutagens corresponding to the retention times of HAs are indicated. Retention tımes of synthetic HAs are: Glu-P-2, 11.3 min; IQ, 11.6 min; IQx, 11.8 min; MeIQ, 14.3 min; MeIQx, 15.1 min; Glu-P-1, 15.3 min; 7,8-DiMeIQx, 17.2 min; 4,8-DiMeIQx, 18.3 min; norharman, 21.1 min; harman, 23.1 min; Trp-P-2, $25.9 \mathrm{~min}$; PhIP, $26.4 \mathrm{~min}$; Trp-P-1, $27.3 \mathrm{~min}$. Retention times of HAs differed due to the complexity of the sample. 

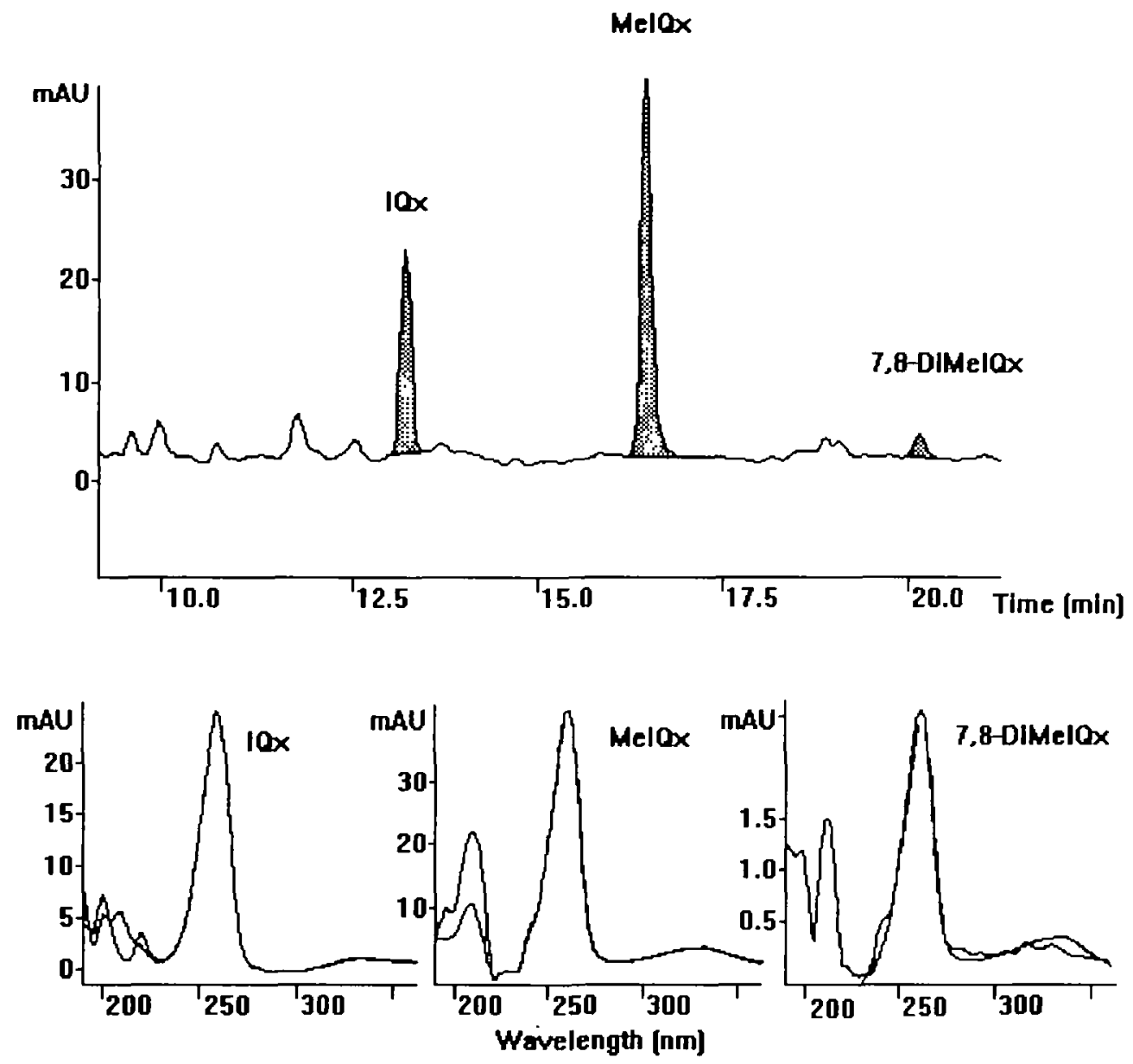

Figure 2. Expanded region of a UV chromatogram (wavelength $263 \mathrm{~nm}$ ) from HPLC analysis of a heated model mixture containing tyrosıne. Peaks corresponding to known HAs are indicated. On-line recorded UV spectra compared with those of synthetic IQx, MeIQx and 7,8-DiMeIQx.

a photodiode array and a time programmable fluorescence detector (HP 1046A) connected in series. Chromatographic conditions were as above. UV detection was perforned at $263 \mathrm{~nm}$ while excitation/emission wavelengths were 360/450 nm for Glu-P-1 and Glu-P-2, 300/440 nm for harman and norharman, 265/410 nm for Trp-P-1 and Trp-P-2 and 315/390 nm for PhIP. Aliquots of $10 \mu \mathrm{l}$ from $200 \mu \mathrm{l}$ of the purified samples were injected.

HAs were identified by comparing the retention times of the peaks with those of synthetic compounds, namely IQ, IQx, MeIQ, MeIQx, 4,8-DiMeIQx, 7,8-DiMeIQx, PhIP, Glu-P-1, Glu-P-2, Trp-P-1, Trp-P-2, norharman and harman, obtained under the same conditions. In addition, some extracts were also spiked with synthetic compounds before injection. UV spectra of synthetic compounds obtained under the same conditions, together with literature data, were used to confirm the identities of the HAs.

The amounts of HAs were estimated by comparing the HPLC peak area of the chromatographed sample with that of a known amount of standard. The amounts were not corrected for incomplete extraction recovery.

\section{LC/MS analysis of HAs}

HPLC was performed with a Waters 600-MS pump, a Waters 490-MS UV detector and a Waters 717 autosampler injecting $20 \mu \mathrm{l}$ of the sample. The column was a ToyoSoda TSK Gel ODS $80 T M(250 \times 4.6 \mathrm{~mm}$ i.d., $5 \mu \mathrm{m}$ particle size), protected with a pre-column containing the same stationary phase. The mobile phases were as follows: solvent $\mathrm{A}, 10 \mathrm{mM}$ ammonium acetate adjusted with $\mathrm{HCl}$ to $\mathrm{pH} 3.2$; solvent $\mathrm{B}, 10 \mathrm{mM}$ ammonium acetate adjusted with $\mathrm{HCl}$ to $\mathrm{pH} 4.0$; solvent $\mathrm{C}$, acetonitrile. The linear gradient program was as follows: 0-10 min, 5-17\% $\mathrm{C}$ in $\mathrm{A} ; 10-10.1$ min exchange of buffer $B$ for $A ; 10.1-22$ min, 17-55\% $\mathrm{C}$ in $\mathrm{B} ; 22-25 \mathrm{~min}, 55-90 \% \mathrm{C}$ in $\mathrm{B}$. The flow rate was $1 \mathrm{ml} / \mathrm{min}$ and $50 \%$ of the flow was split off before entering the mass spectrometer. MS was performed with a Finnigan TSQ-700 mass spectrometer (Bremen, Germany) equipped with a Finnigan electrospray interface working at the high voltage of $4.5 \mathrm{kV}$. The manifold temperature was $70^{\circ} \mathrm{C}$ and the heated capillary was set at $250^{\circ} \mathrm{C}$. Nitrogen was used as sheath gas at a pressure of $4.8 \mathrm{bar}$. The compounds were detected after monitoring the protonated molecular ions $[\mathrm{M}+\mathrm{H}]^{+}$.

\section{Results}

\section{Formation of mutagenic activity in model mixtures}

The heated model mixtures all showed mutagenic activity in Salmonella typhimurium TA98 with metabolic activation, as shown in Table I. The mutagenic activity ranged from 80 to 2400 revertants $/ \mu \mathrm{mol}$ creatinine. Mixtures containing cysteine, cystine or threonine showed the highest response, while the lowest was found in mixtures containing tryptophan, glutamic acid or phenylalanine. No detectable mutagenic activity was formed in the blank sample.

HPLC fractions were tested for mutagenic activity to determine the number of mutagenic compounds and to compare the elution times of the mutagenic components with those of known HAs. Figure 1 shows the mutagenic activity profiles for heated samples containing different amino acids. Each profile contained two to seven mutagenic peaks, some of which elute at similar retention times to those of known HAs found in the pyrolysis products of foods. The mutagenic compounds co-eluting with known HAs are indicated in Figure 1.

\section{Identification of mutagenic compounds}

By comparing the retention times of the mutagenic peaks with those of known HAs and by using HPLC UV spectrometry and LC/MS analysis, the presence of several known HAs in the various model systems was established. Figures 2 and 3 show chromatograms obtained from a heated model sample containing tyrosine from HPLC and LC/MS analyses respect- 

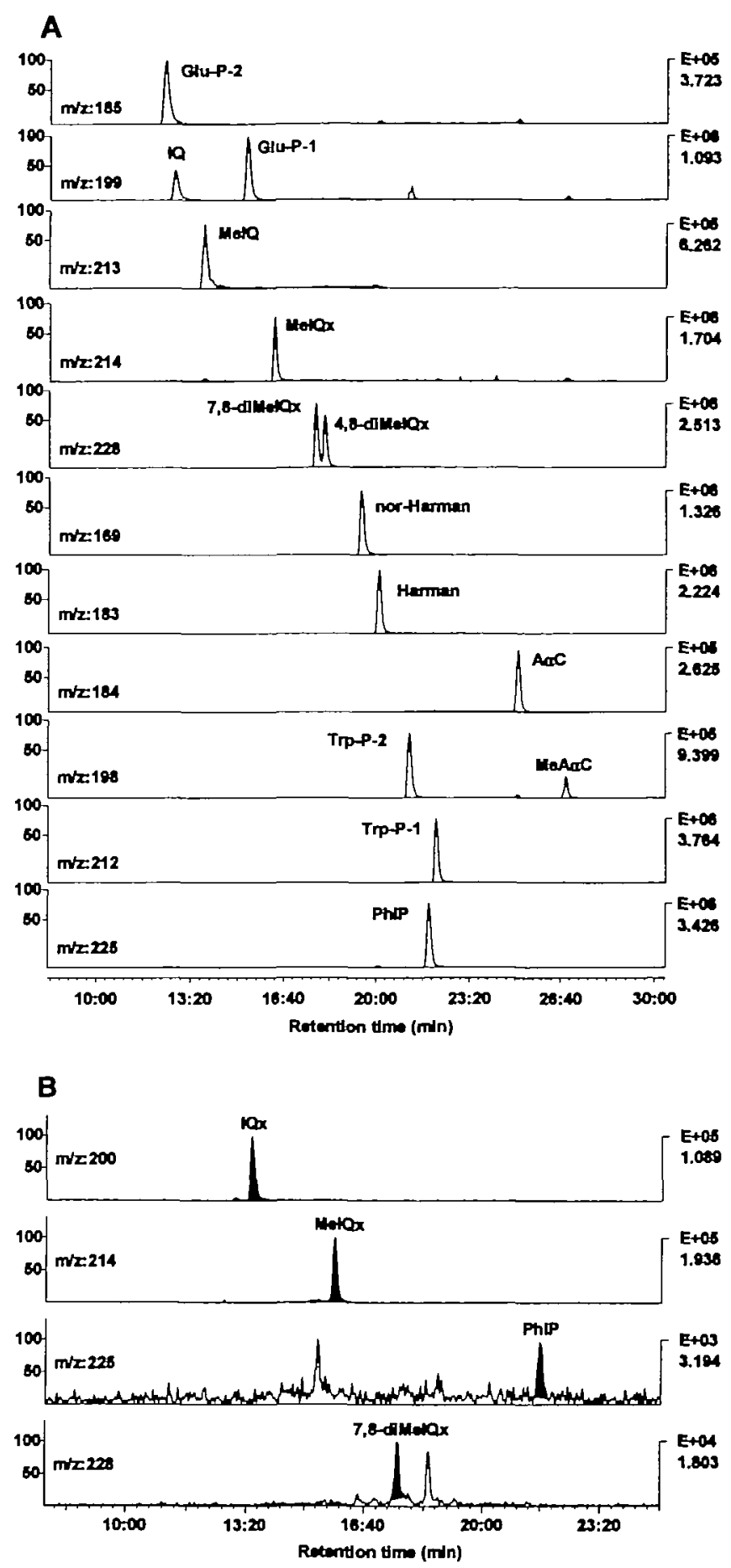

Figure 3. LC/MS analysis of a model system. (A) Selected ion monitoring of reference HAs at the respective $m / z[\mathrm{M}+\mathrm{H}]^{+}$ions. (B) Analysis of a sample contaınıng tyrosine. The chromatogram displays the expanded region contauning IQx, MeIQx, PhIP and 7,8-DiMeIQx (shadowed).

ively. A comparision of UV absorption spectra of the tyrosine sample and those of synthetic references is also shown in Figure 2. As shown in Table II, IQx, MeIQx and 7,8-DiMeIQx were present in most of the heated model mixtures. In addition, 4,8-DiMeIQx was detected in samples containing alanine, threonine, lysine, phenylalanine or methionine. We failed to confirm the presence of IQx with LC/MS in some samples, due to unstable signals (Table II). Norharman and harman were formed in samples containing isoleucine, arginine, phenyl-
Table II. Estimated amounts ( $\mu \mathrm{mol} / \mathrm{mol}$ creatınine) of IQx, MeIQx and 7,8DiMeIQx formed in heated mixtures of glucose, creatinine and amino acids analysed using HPLC with photodiode array detection

\begin{tabular}{llll}
\hline Amino acid & IQx & MeIQx & 7,8-DiMeIQx \\
\hline Glycine & $3.1 \pm 0.8$ & $3.6 \pm 1.2$ & 0.3 \\
Alanine & $5.0^{\mathrm{a}}$ & $5.4 \pm 5.1$ & 0.7 \\
Valine & $\mathrm{c}$ & $4.7 \pm 3.5$ & $\mathrm{c}^{\mathrm{b}}$ \\
Leucine & $\mathrm{c}^{\mathrm{a}}$ & 2.4 & $\mathrm{c}$ \\
Isoleucine & $\mathrm{c}$ & $2.7 \pm 0.7$ & $\mathrm{c}$ \\
Serine & $6.5^{\mathrm{a}}$ & $3.0 \pm 1.7$ & 0.1 \\
Threonine & $4.5^{\mathrm{a}}$ & $9.2 \pm 2.1$ & $\mathrm{c}$ \\
Aspartic acid & $\mathrm{c}^{\mathrm{a}}$ & $0.8 \pm 0.6$ & \\
Asparagine & $2.9^{\mathrm{a}}$ & 1.5 & 0.2 \\
Glutamine & 1.4 & 0.6 & $\mathrm{c}$ \\
Lysine & $\mathrm{c}^{\mathrm{a}}$ & $7.7 \pm 3.7$ & $\mathrm{c}$ \\
Arginine & $3.7 \pm 0.3$ & $4.1 \pm 0.7$ & $\mathrm{c}^{\mathrm{a}}$ \\
Histidine & 1.8 & $3.4 \pm 3.2$ & $\mathrm{c}^{\mathrm{a}}$ \\
Phenylalanine & $1.5 \pm 0.3$ & $1.9 \pm 0.7$ & 0.1 \\
Tyrosine & $2.6 \pm 2.3$ & $3.6 \pm 2.1$ & $\mathrm{c}$ \\
Tryptophan & 0.7 & $5.0 \pm 3.5$ & $\mathrm{c}$ \\
Cysteine & & $\mathrm{c}$ & \\
Cystine & 0.1 & $\mathrm{c}$ & \\
Methionine & $0.9^{\mathrm{a}}$ & $2.7 \pm 0.5$ & $\mathrm{c}$ \\
Proline & & & $\mathrm{c}^{\mathrm{a}}$ \\
\hline
\end{tabular}

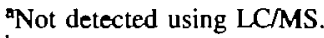

$\mathrm{b}_{\mathrm{c}}$, co-eluting compounds interfered with peak area determination. Amounts are means from the analysis of duplicate samples. LC/MS with electrospray interface and single ion monitorng was used for the detection of the compounds.

alanine or tryptophan. Norharman was also formed in a model mixture with tyrosine. PhIP was found in model mixtures containing phenylalanine, isoleucine or tyrosine. Trp-P-1 and Trp-P-2 were found in a model mixture containing tryptophan. Trp-P-1 was also detected in the isoleucine sample. IQ, MeIQ, Glu-P-1 and Glu-P-2 were not found in any of the samples. No known HAs were found in the glutamic acid and hydroxyproline samples or in the blank sample. However, several unknown mutagenic components were present in the heated samples.

\section{Quantification of HAs}

The amounts of HAs in the samples were estimated from the UV and fluorescence chromatograms and are shown in Table II for IQx, MeIQx and 7,8-DiMeIQx; their maximum yields were $6.5,9.2 \pm 2.1$ and $0.7 \mu \mathrm{mol} / \mathrm{mol}$ creatinine respectively. Samples containing arginine, glycine or tyrosine produced large amounts of IQx. Most MeIQx was formed in the sample containing threonine, followed by samples containing lysine, tryptophan and alanine. The alanine-containing sample produced $1.1 \mu \mathrm{mol} 4,8-\mathrm{DiMeIQx} / \mathrm{mol}$ creatinine, while $7.3 \pm 4.2$ $\mu \mathrm{mol} \mathrm{PhIP} / \mathrm{mol}$ creatinine were produced in the phenylalaninecontaining sample. Due to co-eluting compounds, it was impossible to estimate the amounts of HAs, especially 7,8DiMeIQx and 4,8-DiMeIQx, in some of the samples. The amounts of norharman, harman, Trp-P-1 and Trp-P-2 were not determined. The amounts of HAs given in Table II are not corrected for incomplete extraction recovery. Extraction of similar model mixtures gave a recovery of $52-97 \%$ for MeIQx $(19,22)$.

\section{Discussion}

The hypothesis for the formation of IQ compounds in Scheme 1 postulated that creatine forms the 2 -aminoimidazo part by cyclization and dehydration. The quinoline/quinoxaline part of 
the molecule arises from pyridines or pyrazines and Strecker aldehydes, formed in the Maillard reaction (18). Surprisingly, neither IQ nor MeIQ was found in any of the samples. This implies that no pyridines are formed in the model system. IQ and MeIQ have previously been detected in model systems with fructose $(26,27)$ and in dry heating experiments (for a review see 3 ).

Amino acids act as precursors of HAs by serving as a nitrogen source in pyrazine formation (28). They also seem to provide the carbon and, in some cases, the methyl group at position 4 (18). According to the hypothesis, glycine is a precursor of IQ, MeIQx and 7,8-DiMeIQx, while alanine might give MeIQ and 4,8-DiMeIQx. However, in this study IQx, MeIQx and 7,8-DiMeIQx were formed from most amino acids, including alanine, when heated with glucose and creatinine in the model system. Moreover, 4,8-DiMeIQx was formed not only from alanine, but also from threonine, lysine, phenylalanine and methionine.

Some of these results are hard to reconcile with the hypothesis illustrated in Scheme 1. However, several amino acids are derivatives of alanine carrying an electropositive group (E), e.g. a heteroatom with a free electron pair or an aromatic ring with $\pi$ electrons. These amino acids, e.g. serine, threonine, cysteine, cystine, phenylalanine, tyrosine, tryptophan and histidine, might undergo retroaldolization to glycine,

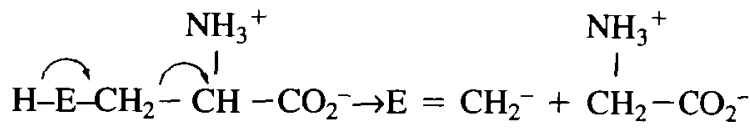

thereby explaining the formation of IQx, MeIQx and 7,8DiMeIQx. The other retroaldolization product $\left(\mathrm{E}=\mathrm{CH}_{2}\right)$ of threonine is acetaldehyde, which could explain the formation of 4,8-DiMeIQx from threonine. Less reactive retroaldolization products are expected from aromatic amino acids. This might explain why IQx compounds with an aryl group at position 4 have never been observed. It is more difficult to guess which reactions valine, leucine, isoleucine, methionine, asparagine, glutamine, aspartic acid, glutamic acid, proline and hydroxyproline undergo in the model system. One possibility might be that these molecules fragment through free radical reactions. Clearly, the observed IQx compounds do not always fit the hypothesis in Scheme 1 and other reaction pathways cannot be excluded. The divergence might be explained by the preferred formation of other HAs, such as PhIP from phenylalanine and Trp-P-1 and Trp-P-2 from tryptophan.

Pyrazines arise through cyclodimerization of aminodeoxy sugars, formed from $\alpha$-dicarbonyl compounds and amino acids in the Strecker degradation (29). The yield and species of pyrazines vary with the amino acid $(28,30-33)$. Sugars are known to fragment through retroaldol or related reactions. If fragmentation precedes pyrazine formation, glyoxal, methylglyoxal and/or biacetyl serve as $\alpha$-dicarbonyl sources. Methylglyoxal is the most common source, giving rise to 2,5dimethylpyrazine, which is the precursor of MeIQx and 4,8DiMeIQx. If glyoxal and methylglyoxal co-dimerize, methylpyrazine, which is the precursor of IQx, is formed. If methylglyoxal and biacetyl co-dimerize, trimethylpyrazine, which is the precursor of 7,8-DiMeIQx, is obtained. Consequently, a mixture of glyoxal, methylglyoxal and biacetyl may have been present in our model mixtures, thus giving rise to IQx, MeIQx, 4,8-DiMeIQx and 7,8-DiMelQx. However, the methylpyrazines may also have formed through initial cyclodimerization,
Table III. Literature data on heterocyclic amines in model systems from amino acids and creatin(1n)e with and without sugar

\begin{tabular}{|c|c|c|c|c|c|}
\hline $\begin{array}{l}\text { Amino } \\
\text { acid }\end{array}$ & Sugar & $\mathrm{HA}$ & Yield $^{1}$ & $\begin{array}{l}\text { Model } \\
\text { system }^{2}\end{array}$ & Ref. no. \\
\hline \multirow[t]{11}{*}{ Gly } & Fru & IQ & 1.0 & reflux & (27) \\
\hline & Glc & IQx & nd & $\mathrm{H}_{2} \mathrm{O}$ & (22) \\
\hline & Glc & MelQx & 4.4 & reflux & (38) \\
\hline & Fru & MeIQx & $6-7$ & reflux & (27) \\
\hline & Glc & MeIQx & 4 & DEG & (35) \\
\hline & Glc & MeIQx & $8.8-17.9$ & $\mathrm{H}_{2} \mathrm{O}$ & (19) \\
\hline & Glc & MeIQx & $7-10$ & $\mathrm{H}_{2} \mathrm{O}$ & (20) \\
\hline & Glc & 4,8-DiMeIQx & nd & DEG & (35) \\
\hline & Glc & 4,8-DiMeIQx & nd & $\mathrm{H}_{2} \mathrm{O}$ & (19) \\
\hline & Gle & 7,8-DiMeIQx & 1.1 & reflux & (39) \\
\hline & Glc & 7,8-DiMelQx & nd & DEG & (35) \\
\hline \multirow[t]{7}{*}{ Ala } & Fru & MelQ & nd & reflux & (26) \\
\hline & Glc & MeIQ & 0.9 & reflux & (40) \\
\hline & Rib & MeIQ & 1.8 & reflux & $(40)$ \\
\hline & - & MeIQ & nd & dry & (34) \\
\hline & Fru & 4,8-DiMeIQx & $1.9-2.6$ & reflux & (26) \\
\hline & Glc & 4,8-DiMeIQx & 4.2 & reflux & $(40)$ \\
\hline & Rib & 4,8-DiMeIQx & 1.5 & reflux & $(40)$ \\
\hline Leu & - & $\mathrm{PhIP}$ & nd & dry & (34) \\
\hline \multirow[t]{3}{*}{ Ser } & - & IQ & 3.7 & dry & (41) \\
\hline & - & IQx & 2.7 & dry & (4) \\
\hline & - & MeIQx & nd & dry & (34) \\
\hline \multirow[t]{5}{*}{ Thr } & Glc & $\mathrm{IQx}$ & nd & $\mathrm{H}_{2} \mathrm{O}$ & (20) \\
\hline & Glc & MeIQx & nd & reflux & (42) \\
\hline & Glc & MeIQx & 9 & $\mathrm{H}_{2} \mathrm{O}$ & (20) \\
\hline & Glc & 4,8-DiMeIQx & nd & reflux & (42) \\
\hline & Glc & 4,8-DiMeIQx & 30 & $\mathrm{H}_{2} \mathrm{O}$ & (20) \\
\hline \multirow[t]{2}{*}{ Lys } & Rib & MelQx & 4.2 & reflux & $(40)$ \\
\hline & Rib & 4,8-DiMeIQx & 26.1 & reflux & (40) \\
\hline Tyr & - & MeIQx & nd & dry & (34) \\
\hline \multirow[t]{10}{*}{ Phe } & - & IQ & 3.0 & dry & (43) \\
\hline & Glc & $\mathrm{IQ}$ & 13.5 & dry & (43) \\
\hline & Glc & MelQx & nd & DEG & (44) \\
\hline & Glc & 4,8-DiMelQx & nd & DEG & (44) \\
\hline & Glc & PhIP & 3.6 & reflux & (45) \\
\hline & - & PhIP & 735 & dry & (42) \\
\hline & Glc & $P h I P$ & 560 & dry & (42) \\
\hline & - & $\mathrm{PhIP}$ & nd & dry & (34) \\
\hline & Glc & $\mathrm{PhIP}$ & 20.9 & DEG & (44) \\
\hline & - & $\mathrm{PhIP}$ & 6.4 & DEG & (44) \\
\hline Pro & - & IQ & 0.4 & dry & (46) \\
\hline
\end{tabular}

${ }^{1}$ Yield in $\mathrm{nmol} / \mathrm{mmol}$ creatin(in)e.

nd $=$ Not determined.

${ }^{2} \operatorname{Reflux}=$ reflux-boiling in diethylene glycol/water $(5: 1)$ at $125-128^{\circ} \mathrm{C}$ for $2 \mathrm{~h} ; \mathrm{H}_{2} \mathrm{O}=$ heated in $\mathrm{H}_{2} \mathrm{O}$ in sealed test-tubes at $180^{\circ} \mathrm{C}$ for $10 \mathrm{~min}$; $\mathrm{DEG}=$ heated in deithylene glycol/water $(5: 1)$ at $180^{\circ} \mathrm{C}$ for $10 \mathrm{~min}$; $\mathrm{dry}=\mathrm{dry}$ heating at $180^{\circ} \mathrm{C}$ for $1 \mathrm{~h}$.

followed by fragmentation of the pyrazine substituents.

All amino acids tested produced mutagenic activity to a varying extent when heated with creatinine and glucose in a model system. The mutagenic activity was generally higher than reported earlier. When various amino acids, creatine and glucose were boiled under reflux in aqueous diethylene glycol for $2 \mathrm{~h}$ at $128^{\circ} \mathrm{C}$ only samples containing threonine, glycine or lysine produced mutagenic activity exceeding 200 TA98 revertants/ $\mu \mathrm{mol}$ creatine (18). Mixtures containing cysteine and cystine, which produced the highest mutagenic activity in the present study, only showed weak mutagenic activity in our previous study. One explanation might be that a closed model system was used in the present study, preventing volatile intermediates from vaporizing. In another study by Övervik et al. (34) various amino acids produced much lower mutagenic activity after dry heating $\left(1 \mathrm{~h} \mathrm{at} 200^{\circ} \mathrm{C}\right)$ with creatine in the absence of sugar. In that study samples with serine or threonine 
showed the highest mutagenic activity. However, serine and threonine are known to decarboxylate and produce pyrazines through dimerization when heated (29).

Comparing our results with previous studies on the formation of HAs in model systems containing various amino acids (see Table III) shows both similarities and differences. However, different kinds of model systems have been used, e.g. dry heating at $180^{\circ} \mathrm{C}$ for $2 \mathrm{~h}$, reflux boiling in diethylene glycol/ water at $125-128^{\circ} \mathrm{C}$ for $2 \mathrm{~h}$, heating in diethylene glycol/water at $180^{\circ} \mathrm{C}$ for $10 \mathrm{~min}$ in open test tubes and heating in water at $180^{\circ} \mathrm{C}$ for $10 \mathrm{~min}$ in sealed test tubes.

To our knowledge, this is the first study reporting the formation of IQx and 7,8-DiMeIQx from most amino acids tested (for a review see 3 ). In addition, several unknown mutagenic components were present in the heated samples. New mutagenic compounds have been first identifed in model systems and later identified in cooked foods (35-37). Much still remains to be done before the complex reaction mechanisms behind the formation of HAs is totally elucidated and the unknown mutagenic compounds are identified.

\section{Acknowledgements}

We thank Mr Santo Ali for his excellent technical assistance. This study was supported by the Swedish Cancer Foundation (1824-B93-10XBC) and the Swedish Council for Forestry and Agricultural Research (50.00440/91).

\section{References}

1. Sugimura,T. et al. (1977) Mutagens-carcinogens in food, with special reference to highly mutagenıc pyrolytic products in broiled foods. In Hiatt,H.H., Watson,J.D. and Winsten,J.A. (eds), Origins of Human Cancer. Cold Spring Harbor Laboratory Press, Cold Spring Harbor, NY, pp. 1561-1577.

2. Felton,J.S. and Knize,M.G. (1991) Occurrence, identification and bacterial mutagenicity of heterocyclic amines in cooked foods. Mutat. Res., 259, 205-217.

3. Skog,K. (1993) Cookıng procedures and food mutagens: a literature review. Fd Chem Toxicol., 31, 655-675.

4. Sugimura,T. and Sato,S. (1983) Mutagens-carcinogens in food. Cancer Res., 43 (suppl.), 2415s-2421s.

5. Felton,J.S. and Hatch,F.T. (1986) Mutagens in cooked foods. Energy Technol. Rev., 1-15.

6. Knıze,M.G., Roper,M., Shen,N.H. and Felton,J.S. (1990) Proposed structures for an amino-dimethylimidazofuropyridine mutagen in cooked meat. Carcinogenesis, 11, 2259-2262.

7. Ohgaki,H., Takayama,S. and Sugimura,T. (1991) Carcinogenicities of heterocyclic amines in cooked food. Mutat. Res., 259, 399-412.

8. Adamson,R.H., Thorgeirsson,U.P., Snyderwine,E.G., Thorgeirsson,S.S., Reeves,J., Dalgard,D.W., Takayama,S. and Sugimura,T. (1990) Carcinogenicity of 2-amino-3-methylimidazo[4,5-f)quinoline in nonhuman primates: induction of tumors in three macaques. Jpn. J. Cancer Res., 81 , $10-14$.

9. Norell,S.E., Ahlbom,A., Erwald,R., Jacobson,G., Lindberg-Navier,I., Olin,R., Törnberg,B. and Wiechel,K.L. (1986) Diet and pancreatic cancer: a case-control study. Am. J. Epidemiol., 124, 894-902.

10. Schiffman,M.H. and Felton,J.S. (1990) Fried foods and risk of colon cancer. Letter to the Editor. Am. J. Epidemiol., 131, 376-378.

11. Steineck, G., Hagman,U., Gerhardsson de Verdier,M. and Norell,S.E. (1990) Vitamın A supplements, fried foods, fat and urothelial cancer. A casereferent study in Stockholm in 1985-87. Int. J. Cancer, 45, 1006-1011.

12. Steineck,G., Gerhardsson de Verdier,M. and Overvik,E. (1993) The epidemiological evidence concerning intake of mutagenic activity from fried surface and the risk of cancer cannot justify preventive measures. Eur. J. Cancer Prev., 2, 293-300.

13. Willett,W.C., Stampfer,M.J., Colditz,G.A., Rosner,B.A. and Speizer,F.E. (1990) Relation of meat, fat and fiber intake to the risk of colon cancer in a prospective study among women. New EngL. J. Med., 1664-1672.

14. IARC (1988) Some Naturally Occurring and Synthetic Food Components, Furacoumarines and Ultraviolet Radiation. IARC monographs on the evaluation of the carcinogenic risk of chemicals to humans Vol. 40 , International Agency for Research on Cancer, Lyon, France.

15. IARC (1993) Some Naturally Occurring Aromatic Amines and Mycotoxins.
IARC monographs on the evaluation of the carcinogenic risk of chemicals to humans Vol. 56, Intemational Agency for Research on Cancer, Lyon, France.

16.Layton,D.W., Bogen,K.T., Knize,M.G., Hatch,F.T., Johnson,V.M. and Felton,J.S. (1995). Cancer risk of heterocyclic amines in cooked foods: an analysis and implications for research. Carcinogenesis, 16, 39-52.

17. Jägerstad,M., Skog,K., Grivas,S. and Olsson,K. (1991) Formation of heterocyclic amines using model systems. Mutat. Res., 259, 205-218.

18. Jägerstad,M., Laser Reuterswärd,A., Öste,R., Dahlqvist,A., Grivas,S., Olsson,K. and Nyhammar,T. (1983) Creatinine and Maillard reaction products as precursors of mutagenic compounds formed in fried beef. In Waller,G.R. and Feather,M.S. (eds), The Maillard Reaction in Foods and Nutrition. ACS Symposium Series 215, American Chemical Society, Washington, DC, pp. 507-520.

19. Johansson, M. and Jugerstad,M. (1993) Influence of oxidized deep-frying fat and iron on the formation of food mutagens in a model system. $F d$ Chem. Toxicol., 31, 971-979.

20. Skog,K. and Jugerstad,M. (1993) Incorporation of carbon atoms from glucose into the food mutagens MeIQx and 4,8-DiMeIQx using ${ }^{14} \mathrm{C}$ labelled glucose in a model system. Carcinogenesis, 14, 2027-2031.

21. Gross,G.A. (1990) Simple methods for quantifyıng mutagenic heterocyclic aromatic amines in food products. Carcinogenesis, 11, 1597-1603.

22. Johansson,M., Skog,K. and Jägerstad,M. (1993) Effects of edible oils and fatty acids on the formation of mutagenic heterocyclic amines in a model system. Carcinogenesis, 14, 89-94.

23. Ames,B.N., McCann,J. and Yamasaki,E. (1975) Methods for detecting carcinogens and mutagens with the Salmonella mammalian-microsomal mutagenicity test. Mutat. Res., 31, 347-364.

24. Maron,D.M. and Ames,B.N. (1983) Revised methods for the Salmonella mutagenicity test. Mutat. Res., 113, 173-215.

25. Bjeldanes,L.F., Grose,K.G., Davis,P.H., Stuermer,D.H., Healy,S.K. and Felton,J.S. (1982) An XAD-2 resin method for efficient extraction of mutagens from fried ground beef. Mutat. Res., 105, 43-49.

26. Grivas,S., Nyhammar,T., Olsson,K. and Jägerstad,M. (1985) Formation of a new mutagenic DiMeIQx compound in a model system by heating creatunine, alanine and fructose. Mutat. Res., 151, 171-183.

27. Grivas,S., Nyhammar,T., Olsson,K. and Jagerstad,M. (1986) Isolation and identification of the food mutagens IQ and MeIQx from a heated model system of creatinine, glycine and glucose. Fd Chem., 20, 127-136.

28. Koehler,P.E., Mason,M.E. and Newell,J.A. (1969) Formation of pyrazine compounds in sugar-amino acid model systems. J. Agric. Fd Chem., 17, 393-396.

29. Baltes,W. and Bochmann,G. (1987) Model reactions on roast aroma formation. 1. Reaction of serine and threonine with sucrose under the conditions of coffee roasting and identification of new coffee aroma compounds. J. Agric. Fd Chem., 35, 340-346.

30. Koehler,P.E. and Odell,G.V. (1970) Factors affecting the formation of pyrazine compounds in sugar-amine reactions. J. Agric. Fd Chem., 18, 895-898.

31. Adrian,J. (1976) La réaction de Maillard vue sous l'angle nutrionnel. Revue Française Dietetique, 76, 7-30.

32. Piloty,M. and Baltes,W. (1979) Untersuchungen zur Reaktion von Aminosäuren mit $\alpha$-Dicarbonylverbindungen. Z Lebensm. Unters. Forsch., 168, 368-373.

33. Arnoldi,A., Arnoldi,C., Baldi,O. and Griffini,A. (1988) Flavor components in the Maillard reaction of different amino acids with fructose in cocoa butter-water. Qualitative and quantitative analysis of pyrazines. J. Agric. Fd Chem., 36, 989-992.

34. Overvık,E., Kleman,M., Berg,I. and Gustafsson,J.-A. (1989) Influence of creatine, amino acids and water on the formation of the mutagenic heterocyclic amines found in cooked meat. Carcinogenesis, 10, 2293-2301.

35. Skog,K. and Jägerstad,M. (1990) Effect of monosaccharides and disaccharides on the formation of food mutagens in model systems. Mutat. Res., 25, 263-272.

36. Knize,M.G., Hopmans,E. and Happe,J.A. (1991) The identification of a new heterocyclic amine mutagen from a heated mixture of creatine, glutamic acid and glucose. Mutat. Res., 260, 313-319.

37. Skog,K., Knize,M.G., Felton,J.S. and Jagerstad,M. (1992) Formation of new heterocyclic amine mutagens by heating creatinine, alanine, threonine and glucose. Mutat. Res., 268, 191-197.

38. Jägerstad,M., Olsson,K., Grivas,S., Negishi,C., Wakabayashi,K., Tsuda,M., Sato.,S. and Sugımura,T. (1984) Formation of 2-amino-3,8dimethylimidazo $[4,5-f]$ quinoxaline in a model system by heating creatinine, glycine and glucose. Mutat. Res., 126, 239-244.

39. Negishi,C., Wakabayashi,K., Tsuda,M., Sato,S., Sugimura,T., Saito,H., Maeda,M. and Jagerstad,M. (1984) Formation of 2-amino-3,7,8-

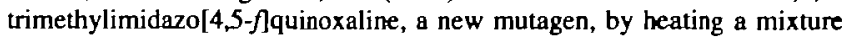


of creatine, glucose and glycine. Mutat. Res., 140, 55-59.

40. Muramatsu,M. and Matsushima,T. (1985) Formation of MeIQx and 4,8DiMelQx by heating mixtures of creatinine, amino acids and monosaccharides (abstract). Mutat. Res., 147, 266-267.

41. Knize,M.G., Shen,N.H. and Felton,J.S. (1988) The production of mutagens in cooked foods. Proc. Air Pollution Control Ass., April, 88-130.

42. Negishi,C., Wakabayashi,K., Yamaizumi,., Saito.H., Sato,S. and Jagerstad,M. (1985) Identification of 4,8-DiMeIQx, a new mutagen (abstract). Mutat. Res., 147, 267-268.

43. Felton,J.S. and Knize,M.G. (1990) Heterocyclic-amine mutagens' carcinogens in foods. In Cooper,C.S. and Grover,P.L. (eds), Handbook of Experimental Pharmacology, Vol. 94/. Springer-Verlag, Berlin, Germany, pp. 471-502.

44. Skog,K. and Jagerstad,M. (1991) Effect of glucose on the formation of PhIP in a model system. Carcinogenesis, 12, 2297-2300.

45. Shioya,M., Wakabayashi,K., Sato,S., Nagao,M. and Sugimura,T. (1987) Formation of a mutagen, 2-amino-1-methyl-6-phenylimidazo[4,5blpyridine (PhIP) in cooked beef, by heating a mixture containing creatinine, phenylalanine and glucose. Mutat. Res., 191, 133-138.

46. Yoshida,D., Sato, Y. and Mizusaki,S. (1984) Isolation of 2-amino-3-methylimidazo[4,5-f]quinoline as a mutagen from the heated product of a mixture of creatine and proline. Agnc. Biol. Chem., 48, 241-243.

Received on March 7, 1995; revised on Jure 16, 1995; accepted on June 16, 1995 